\title{
INFORMATION BEHAVIOUR OF UNIVERSITY STUDENTS
}

\author{
Eva Ortoll-Espinet (1), Aurora González-Teruel (2), Esther Gilabert-Ros (2)
}

(1) Universitat Oberta de Catalunya. Information Science and Communication Sciences Department. Spain (eortoll@uoc.edu)

(2) History of Science and Documentation Department, University of Valencia. Spain (agonzal@uv.es)

\begin{abstract}
This work presents the preliminary results of an information behaviour study of students in two Spanish universities. A qualitative methodology was adopted and the results analysed following the grounded theory. The results were classified according to the reasons that motivated the information seeking behaviour, the means used for their resolution and the results of the search process. The use of a qualitative perspective allowed us to obtain a general picture of university students' information problems. Future lines of research are determined, and the results include a future research agenda.
\end{abstract}

Keywords: Information behaviour, qualitative methodology, university students

\section{Introduction}

European universities, and among them Spanish universities, began a convergence process toward a European Higher Education Area (EHEA) in 1999, through the Bologna Accords. This process will conclude in 2010 with a new university model. This model envisages management structures configured around an education focused on students' learning processes. Information technologies will play a fundamental role in those processes.

This direction change presupposes that the main organizations providing information should consider designing services focused on the students, who are to be the main focus of university activity. This direction change will therefore affect the bibliographic supplier and information services and also those aspects of administration which, although related to non-pedagogical information, are necessary for the academic management of the students.

For the planning and design of these services, research into and study of students' information behaviour is required. It is of vital importance to take this into consideration at an early stage, especially in the early phases of information system development, for two reasons. First, because it enables the integration the information needs of future users into the definition of the mission and the goals of the information system. Secondly, because involving these future users in the process of change will help to reduce their reticence to that change.

We should not forget, moreover, that part of the EHEA philosophy is focussed on the importance of multiple subject competences. This not only facilitates useful interaction with the information systems but also the autonomy of information management for all aspects of professional and personal life.

\section{a) Literature review}

According to a recent survey of bibliographical sources, an average of $9.8 \%$ of research reported in the field of information needs and uses in Spain in the period 1990-2004 is centred on the university context (González Teruel and Abad García, 2007). In general, these works study the use of a service (Perea Vega, 2002), the use of an information resource (Ferrán Ferrer, N, et al 2007), the use of the information (Urbano Salido, 2000) or satisfaction with the use of an information system (Villarejo Sánchez, 2004).

However, a system-centred perspective, focused on a quantitative methodology, with a partial view of the information search process, although useful for the evaluation of those systems, is not adequate for its planning and improvement. More recently, in a study of undergraduate student information behaviour, with EHEA already envisaged, Pinto and Sales (2007) adopted a 
perspective more focused on the user. In this case, for students studying translation, the objective is the design of learning programmes rather than the planning of information systems. Also, we found one work (Arquero Avilés, et al, 2007) focused on planning CRAI (Learning Resources Centre) at the Universidad Complutense de Madrid. This work has as its objective the incorporation of information needs in the process of mission definition, goals and objectives.

Finally, in the Spanish context, we can cite the more inclusive work of Cobarsí et al (2008) on campus information systems at Spanish universities. The perspective proposed in this research is to seek a broad vision of the information services used by university students. In this work, the authors present the operative definition of the Campus Information Systems for students in the following way: an interrelated group of information resources, accessible by computer through the campus institutional web support, both internal and external, that a university places at the disposal of its users to enable them to consult it and/or provide a selection of significant and relevant data, in the broad context of their university life in its academic, administrative and social senses, in order to improve students' knowledge base" (pp. 52).

At an international level, it is possible to find more works centred on the study of information behaviour of university students during their academic activities. These works are undertaken from a user perspective and with a qualitative methodological focus. For example, the work of George, et al (2006), carried out by means of semi-structured interviews, demonstrated the need for teachers and librarians to work together. Similarly, Lee (2008) adopts a qualitative methodology to investigate the way that undergraduate students look for information by means of diverse university structures.

\section{a) Methodological approach}

In 1977, in the INISS study, one of the most important and significant in the field of Information Behaviour, Streatfield and Wilson chose the use of investigation-action methodology because the overall result of previous research in this field was that: "..much information-behaviour research had proved to be sterile and unimaginative..". In addition, they used observation and interviews (methodological triangulation) to obtain relevant information that resulted in specific actions related to the information systems of the environment studied.

It can now be seen that this was an early example of a critical position with regard to previous studies centred on users. In these studies, a quantitative position that sought to quantify the transactions between a user and the system had prevailed. Also, sampled and generalised results had been used, usually using self-administered questionnaires. In this sense, Wilson (1999) stated that quantitative research methods were adopted that were inappropriate to the study of human behaviour.

It comes to seem indisputable that there is a need to adopt a holistic perspective of the information seeking process through the use of a qualitative methodology or methodological triangulation (quantitative-qualitative). Thus the qualitative approach or methodological triangulation has had an increased presence in papers presented to ISIC (Information Seeking in Context), the main international conference in this field (Vakkari, 2008). The grounded theory is also of increasing importance in this field. According to Strauss y Corbin (1990), the grounded theory is used when there is a need to go out into the field in order to understand a phenomenon and when the experience is continuously evolving. In this regard, the work of Ellis (1993) is important, the results of which, in terms of contributing to and advancing the study of the information behaviour, lead to one of the most important models of information seeking behaviour. More recently, the work of Razavi and Iverson (2006), centred on the role of personal space in students' learning.

\section{Objectives}

This investigation addresses the following objectives: 
a) To validate the use of a qualitative and inductive approach, the grounded theory, in the study of the information behaviour.

b) To describe the information behaviour of the students of two Spanish universities in two different contexts: a virtual campus (Universitat Oberta de Catalunya - UOC) and an on-site campus (Universitat de València - UVEG) in order to extract practical recommendations for information systems planning according to the user's information needs.

c) To analyse if the university campus characteristics (physical or virtual) have an effect on the students information behaviour.

\section{Procedures}

\section{Study location}

The data was collected from two Spanish universities between February and April 2009. The first, the UOC (Universitat Oberta de Catalunya), uses a virtual learning environment. In this context, the students are trained in the efficient use of the virtual campus. This training is conducted in academic (didactic resources) and administrative environments. The second, the UV (Universitat of València) develops its academic activities on an on-site campus. In recent years, this university has developed various programmes to introduce technology into the learning and academic environment, although academic activities follow a traditional model.

\section{Study subjects}

The objective of this research was not to obtain generalised results, but rather to collect detailed information. That is, this research aimed to discover the various different situations of the university students' information seeking behaviour during their academic life, but did not aim to discover which are the most frequent. Therefore, to obtain the maximum diversity of possible situations, the selection of participants was carried out by means of a purposive sample. Thus, two variables were used to select the cases used: type of studies and credits obtained.

\section{Data collection}

In depth, semi-structured interviews were conducted with university students representing most of the disciplines from UV and UOC. The interviews were carried out in person in the UV and by post in the UOC. The interviews were designed to cover occasions in which there was a need for more information to resolve a situation or problem. Specifically, information was collected related to the following situations: the beginning of university life, carrying out administrative procedures, studying a subject, the use of the university's technological resources, extra-curricular training, seeking grants, seeking employment and participation in extra-academic activities.

\section{Data analysis}

For data analysis, the grounded theory approach was employed (Strauss y Corbin, 1990). This inductive approach facilitates knowledge of the phenomenon studied without theoretical or previous classifications and aims to construct theory based on observation. This approach is useful in information behaviour as a means of initiating the research. To this end, in the preliminary phase, the following tasks were carried out: a) a review of interview results; b) each of the researchers made a proposal of the topics to be analysed by reading and analysing of the data; c) the various categories and the proposed topics were discussed and the researchers agreed on the final classification; d) the collected data was analysed and categorised into three areas: the situation that motivated an information behaviour, the means used for their resolution and the results of the process.

\section{Results}


From the 26 interviews, 83 incidents or information problem situations were gathered, an average of 3 situations per interview. We present below the data analysis results for the two universities studied. The data is analysed together, except in those cases where there are significant differences.

Our analysis enabled us to identify situations that initiate an active process of information seeking and use, and how the students resolved them. The two main important findings that emerged from our analysis were that the key factors affecting the user's information behaviour were interaction with information systems and service expectations.

\subsection{Situations that required an active process of information seeking and use}

\section{1.a. Information problems that required an interaction with Campus Information Systems}

Following the analysis of the 83 situations, we can put the information problems into three categories: a) academic issues related to the courses being taken (22 incidents); b) administrative issues to enable the courses taken to be followed properly (46 incidents) and c) social issues, including in this group problems related to activities such as email connection or other facilities provided by the university, but not linked to courses ( 21 incidents).

Situations related to courses being taken produced data which reflected concerns in three areas: 1) extending the content specific course; 2) course assignment or project; and 3) pedagogical materials for courses.

The problems related to administrative issues produced the greatest variety of incidents described. The students reported problems related to: 1) general administrative office information; 2) starting university; 3) course credit recognition; 4) course enrolment; 5) physical location of classes; 6) timetable; 7) free courses; 8) scholarships and grants; and 9) practicum administration.

Problems related to social issues produced a variety of different situations: 1) campus electronic connection and email management; 2) transport cards and university card; 3) free subject courses or languages courses; and 4) employment seeking.

\section{1.b. Information required}

Analysis of the data suggests that two kinds of information are required to solve the problems in the three areas described above a) academic and bibliographical information related to a course subject and b) organisational information provided by the university and related to their administrative procedures and services.

a) Academic and bibliographical information.

The first type of information is that required to solve the problems identified in the "Academic Issues" category. The information required for each problem concerned:

1) Content extension for a specific subject course: the information required was bibliographical.

2) Course assignment or project: the information required was bibliographical.

3) Course and pedagogical material: the information required was bibliographical and included class notes or other documentation generated by professors.

b) Organisational information.

The second type of information needed was that required to solve the problems identified in the "Administrative Issues" and "Social Issues" categories. The information required for each problem concerned:

1) General administrative office information. 
2) Starting university: students described initial disorientation in the first semester at the university and their information problems were related to identifying university services and their location.

3) Credit course recognition: procedural information.

4) Course enrolment: various types of information problems were described, and were associated with the stages in the procedures: general lack of knowledge about course enrolment process, with special focus on specific situations in the process (payment confirmation, etc.).

5) Physical location of classes: in this situation, although the problems were basically the same, we found some differences between the two kinds of university. The physical university students had problems with class locations, and the virtual university students had problems with the physical location of examination rooms.

6) Timetable: as with the previous situation, we observed a small difference in the kind of problems. The physical university students described problems with the general timetable, and the virtual university students described problems with specific dates in the classroom timetable.

7) Free courses.

8) Scholarship and grants.

9) Practicum administration.

10) Campus electronic connection and email management: procedural information and information required to change passwords.

11) Transport cards and university card, etc.: procedural information.

12) Free subject courses or languages courses: procedural information and information about the courses offered by university.

13) Employment seeking: procedural information.

It is interesting to note that no significant differences were found between the two kinds of universities studied in relation to information problems and the information required to solve them.

\subsection{Information problem resolution}

Our results show that the strategies employed to resolve the information problems were similar in both universities and that the reasons for electing formal or informal information sources depended on which of the three information categories described above were concerned.

a) Academic issues.

The preferred sources described by students when trying to resolve academic information issues were the same in both universities, although there was a difference in the procedure used to obtain pedagogical material: in the virtual university the students have a specific virtual space for that purpose, in the physical university the preferred channel is personal contacts.

The Internet was the preferred means to obtain additional or complementary bibliographical information for a course. The reasons, as previous research has demonstrated, is speed and ease of use. The students are aware of the information quality and credibility of that resource.

Nevertheless, the library and Internet are used equally to find bibliographical information. The motivation to use it is less, however, and the students said they use the Library because they know it is the formal way to obtain information, but they are not comfortable with it. Most students perceive the Library as less useful and use it when no other means is possible.

The most frequently cited barriers associated with Library use are related to the structure of information resources, and the perception that the contents are not sufficiently up to date. Interface barriers are cited by only one student. This shows that the information retrieval process is not the problem, and that the question is more associated with content management and quality criteria. 


\section{b) Administrative issues}

The reasons for selecting specific means of solving administrative information problems are again linked to the speed and ease of use. But in this case, the perception of speed and ease of use is associated with informal channels such as other students and, less frequently, the tutor. The CIS Administrative Office is used only when students perceived it as the only available resource.

The major problems associated with course enrolment were the lack of precise information about the process in the case of the physical university, and on difficulty in understanding the information at different stages of the individual process in the case of the virtual university. This shows that information accuracy and information visualisation is two important features of information systems. One student said that lack of precise information "leads you to enrol in a course you don't really want".

The time spent in finding the correct information is clearly a problem when interacting with SIC, and that expenditure of time produces a lack of confidence in the source. The web information structure is also cited by students as a barrier.

c) Social issues

Curiously, most of the problems related to the Social Issues category were solved by the use of the corresponding SIC. The majority of problems in this category were those linked to electronic campus connection and email management, and also obtaining university cards. The most important reason to select the SIC as the preferred means is that the various procedures involved and the information about them is clear. When information problems are more abstract (job seeking or free courses) other students, the tutor and Internet are the preferred channels.

The principal barrier for this information resource category was the lack of awareness of the information need: "if you don't look for something you don't know that it exits".

\subsection{Grounded theory findings: Campus Information Systems: interaction and expectations as concerns of university students' information behaviour.}

As we noted previously, two main concepts emerge from the data analysis, interaction with and expectations of the Campus Information Systems. These are the fundamental concerns that affect university students' information behaviour. We will proceed to describe how these concepts are reflected in the three categories we defined previously in relation to information problems and resources.

a) Academic issues.

The principal feature for good interaction with CIS is related to better information architecture, with special emphasis on the reduction of web hierarchies. Secondly, content analysis made by university staff, both academics and librarians, is viewed as a value added feature when interacting with the systems, enabling students to have more content abstracts, comments on specific resources, integration of information, information in digital formats and a more detailed evaluation and selection of their utility and contents. Thirdly, students expect a more personalized service.

In general the search process is viewed as a waste of time, insofar as they don't perceive it as important, even if the institution offers instruction on information seeking. As one student said, "the important thing nowadays is not the search process, it is the analysis". In this sense, the data shows that students have a high level of self-confidence to remember the strategy they have used to obtain information and in their ability to repeat the process in futures uses.

So, we can state the following propositions:

P1- The greater the effort invested on a user centred design for the information structure of Campus Information Systems, the more useful the resources will be perceived to be by students. 
P2- The more added value processing with regard to resource contents and formats made by librarians and teachers, more students would use those resources.

b) Administrative issues

In general, CIS - Administrative Office interaction is expected to be more personal, both in aspects such as direct feedback to students and in information visualisation. Another important feature is the time needed for carrying out an interaction with the system. In the virtual university, students have the expectation to obtain information by different means for each specific problem.

CIS - Administrative Office interaction is affected by the degree of accurate information processing. Only one student indicated their role as information provider when engaged on administrative formalities.

The principal expectations of this CIS are again related to information architecture, more accurate information and better information visualisation.

So, we can affirm the following propositions:

P3- The more personalised the information given in relation to Administrative issues, the more user friendly would be the interaction of students with CIS Administrative Office

P4- The more effort made on information accuracy in the CIS - Administrative Office and on the visualisation of personal administrative data information, the less time students would spend doing administrative transactions, and the information service would therefore be perceived as more useful.

c) Social issues

The problems linked with social issues category are, unexpectedly, much more focused, as the information resources are less abundant and clearer. The information process is viewed as more accurate than in the other to CIS categories, except when students are seeking job information.

The interaction with CIS-Social is described as correct and useful, except on those issues related with security features of email or campus electronic connection.

The expectations in this category are concentrated on the accuracy of information related to extra academic activities. Finally, students in the virtual university reported that their expectation was to increase the possibilities of incorporating and making available more formats to manage their personal information with email.

So, we can establish the following proposition

P6- The less abstract is perceived the information needed to solve a problem, the more frequently students use formal channels to access it.

\section{Conclusions}

- Using an inductive qualitative approach in this information behaviour study of the university students allowed us to obtain an overview of problematical situations related to searching and the use of information in academic life. This information will be the starting point of future research into aspects related to the information seeking process of university students. These lines of future research will be developed using concepts from the context observed, without recourse to preconceived ideas, theories or previous classifications.

- More research is required in the field of administrative problems. It becomes clear that the personalisation of information, in both a virtual and actual environment, is a key element of information systems. The students usually search for information about administrative procedures through personal channels. They uses the SIC only to formalise the procedures. 
- In spite of the enormous investment universities have made in the purchase and maintenance of information resources, most students do not perceive the library as a useful service. They prefer the Internet as an information resource. It will be possible to develop a project on this issue related to the implication of the librarian's services with regard to the process of teaching-learning, specifically, on all aspects related to the planning and development of repositories of learning materials. The success of an information system does not depend only on its financial cost or on its technological sophistication, but on its adaptation to the user.

- In summary, in the early phase of this study, results have emerged on various aspects of descriptive and theoretical propositions that can continue to be developed through grounded theory procedures, specifically, open coding and theoretical sampling.

\section{References}

- $\quad$ Arquero Avilés, R., Caballos Villar, A., Cáceres Zapatero, M. D., García-Ochoa Roldán, M. L., Horta García, C., Ramos Simón, L. F., Zornoza Boy, J., (2007): Planificación de Centros de Recursos para el Aprendizaje y la Investigación (CRAI's): un estudio de caso. Boletín de la ANABAD, vol. 57, n², 335357.

- Cobarsí, J., Bernardo, M., Coenders, G., (2008): Campus information system for students: classification in Spain. Campus-Wide Information Systems, vol. 25, $\mathrm{n}^{\circ}$ 1, 50-64.

- Ellis, D., (1993): Modelling the information-seeking patterns of academic researchers: a Grounded Theory approach. Library Quarterly, vol. 63, nº 4, 469-486.

- $\quad$ Ferrán, N., Casadesús, J., Krakowska, M., Minguillón, J., (2007): Enriching e-learning metadata through digital library usage analysis. The Electronic Library, vol. 25, n 2, 148- 165.

- George, C., Bright, A., Hurlbert, T., Linke, E.C., St. Clair, G. Stein, J., (2006): Scholarly use of information: graduate students' information seeking behaviour. Information Research, vol. $11, \mathrm{n}^{\mathrm{o}} 4$, paper 272 [Available at http://InformationR.net/ir/11-4/paper272.html]

- González Teruel, A., Abad García, M. F., (2007): Information needs and uses: an analysis of the literature published in Spain, 1990-2004. Library and information science research, vol. 29, $\mathrm{n}^{\circ}$ 1, 30-46.

- Lee, H. L., (2008): Information structures and undergraduate students. The Journal of Academic Librarianship, vol. 34, no 3, 211-219.

- $\quad$ Razavi, M. N., Iverson, L., (2006): A Grounded Theory of Information Sharing Behavior in a Personal Learning Space. In: Proceedings of the ACM CSCW '06 Conference on Computer Supported Cooperative Work, Banff, Alberta, Canada, November 4 - 8, 2006.

- $\quad$ Perea Vega, G., (2002): La biblioteca de la Universidade da Coruña. Estudio con los alumnos. Revista española de Documentación Científica, vol 25, $\mathrm{n}^{\circ} 1,29-48$.

- Pinto Molina, M. and Sales, D., (2007): A research case study for user-centred information literacy instruction: information behaviour of translation trainees. Journal of Information Science, vol. 33, $\mathrm{n}^{\mathrm{o}} 5$, $531-550$.

- Strauss, A. and Corbin, J., (1990): Basics of qualitative research: Grounded theory procedures and techniques. Newbury Park, Calif: Sage Publications.

- Urbano Salido, C., (2000): Tipología documental citada en tesis doctorales de informática: bases empíricas para la gestión equilibrada de colecciones. BiD-Textos universitaris de Biblioteconomia $i$ Documentació. $\quad 2000, \quad \mathrm{n}^{0} 5 . \quad$ [Available at http://www2.ub.es/bid/consulta_articulos.php?url=http://www.ub.es/biblio/bid/05urban2.htm]

- Vakkari, P., (2008): Trends and approaches in information behaviour research. Information Research, vol. 13, $\mathrm{n}^{\circ}$ 4, paper 361. [Available at http://InformationR.net/ir/13-4/paper361.html]

- Villarejo Sánchez, N., (2004): Evaluación del grado de satisfacción de usuarios fomentado por el OPAC de la biblioteca de la UNED de Talavera de la Reina (Centro Asociado). Revista general de información y documentación, vol. 14, nº1, 193-198.

- Wilson, T. D., (1999): Models in information behaviour research. Journal of Documentation, vol. 55, $\mathrm{n}^{\circ} 3,249-270$.

- Wilson, T. D. and Streatefield, D. R., (1977): Information needs in local authority social services departments: an interim report on project INISS. Journal of Documentation, vol. 33, n%, 277-293. 